\title{
ASSESSING THE IMPACTS OF CLIMATE CHANGE ON TERRESTRIAL ECOSYSTEMS IN BHAVANISAGAR RESERVOIR AND ITS SURROUNDINGS, USING MULTITEMPORAL SATELLITE DATA AND GIS TECHNIQUES
}

\author{
G. Balamurugan ${ }^{1}$, G. Meiyappan ${ }^{2}$, V. Thirukumaran ${ }^{3}$ \\ ${ }^{1}$ Centre for Remote Sensing and Geoinformatics, Sathyabama University \\ ${ }^{2}$ Department of Chemical Engineering, Anna University, Chennai- 60025 \\ ${ }^{3}$ Department of Applied Geology, Government t Arts Collage, Salem-7
}

KEYWORDS: Landsat-TM, ETM+, multitemporal analysis, ecosystem, Land cover changes

\begin{abstract}
:
Despite the warnings against climate change since the early century, recent human activities are still geared towards enhancing them. Because of climate change coupled by other human activities, natural ecosystems are facing difficulties in coping with the impacts of climate change. The evaluation of the impact of climate change on ecosystems implies studying a multi-component system in which the complexity of links is high enough to present doing it as a whole. Because of this, it is a reasonable approach to study separately the behavior of each element, to be afterwards linked into a general conceptual model for ecosystems behavior. Moreover, in the case of largely regulated region, the main impacts of climatic change will be fluvial-related since those related to the catchment areas will be severely damped by river regulation and management policies. This fact implies that Terrestrial fringes may become the main frontier between the ecosystems and climatic change effects. This paper describes the potential impacts of warming temperatures and changing precipitation on vegetation, wildlife, land use/ land covers, and agricultural ecosystems across the Bhavanisagar Reservoir region centered on Coimbatore district, Tamilnadu. We examine a geographic area that captures much of Reservoir, including a complex mosaic of urbanization and agriculture surrounding the Bhavanisagar Reservoir. The comparative study of land cover and soil status are provided using space images with middle resolution. Multitemporal satellite data provide the capability for mapping and monitoring land cover and land use change, but require the development of accurate and repeatable techniques that can be extended to a broad range of environments and conditions. The Landsat TM and ETM + and SRTM-DEM images are included in analysis. The unsupervised and supervised classifications are applied for determination of different types of land cover. The research present here has focus on devising a simple and operational rule-based approach to map land cover changes, based on the classification of Landsat imagery and the conceptual analysis of the information regarding change detection. The use of ancillary GIS data such as Digital Elevation Model, existing thematic maps and the knowledge of the ecosystem dynamics, formed the basis for setting the rules for the post-processing of the classified Multitemporal images that led to a more accurate assessment and mapping of land cover changes. The above framework has proved to be a promising and practical approach in order to quantify, understand, conceptualize and better present the dynamics of land cover/use changes in Terrestrial Ecosystems.
\end{abstract}

